\title{
Impact of centralising acute stroke services in English metropolitan areas on mortality and length of hospital stay: difference-in-differences analysis
}

Stephen Morris professor of health economics ${ }^{1}$, Rachael M Hunter senior research associate ${ }^{2}$, Angus I G Ramsay senior research associate ${ }^{1}$, Ruth Boaden professor of service operations management $^{3}$, Christopher McKevitt reader ${ }^{4}$, Catherine Perry research associate ${ }^{3}$, Nanik Pursani patient representative ${ }^{5}$, Anthony G Rudd professor of stroke medicine ${ }^{6}$, Lee H Schwamm professor of neurology ${ }^{7}$, Simon J Turner senior research associate ${ }^{1}$, Pippa J Tyrrell professor of stroke medicine $^{8}$, Charles D A Wolfe professor of public health medicine ${ }^{49}$, Naomi J Fulop professor of healthcare organisation and management ${ }^{1}$

\begin{abstract}
${ }^{1}$ Department of Applied Health Research, University College London, London WC1E 7HB, UK; ${ }^{2}$ Research Department of Primary Care and Population Health, University College London, London NW3 2PF, UK; ${ }^{3}$ Manchester Business School, University of Manchester, Manchester M15 6PB, UK; ${ }^{4}$ Division of Health and Social Care Research, School of Medicine, King's College London, London SE1 3QD, UK; ${ }^{5}$ King's College London Stroke Research Patients and Family Group, Division of Health and Social Care Research, School of Medicine, King's College London, London SE1 3QD, UK; ' ${ }^{6}$ Guy's and St Thomas' NHS Foundation Trust, St Thomas' Hospital, London SE1 7EH, UK; 'Department of Neurology, Massachusetts General Hospital, Harvard Medical School, Boston, MA, USA; ${ }^{8}$ University of Manchester Stroke and Vascular Centre, Manchester Academic Health Science Centre, Salford Royal Hospitals NHS Foundation Trust, Salford M6 8HD, UK; ${ }^{9}$ National Institute of Health Research Comprehensive Biomedical Research Centre, Guy's and St Thomas' NHS Foundation Trust and King's College London, London, UK
\end{abstract}

\begin{abstract}
Objective To investigate whether centralisation of acute stroke services in two metropolitan areas of England was associated with changes in mortality and length of hospital stay.

Design Analysis of difference-in-differences between regions with patient level data from the hospital episode statistics database linked to mortality data supplied by the Office for National Statistics.

Setting Acute stroke services in Greater Manchester and London, England.

Participants 258915 patients with stroke living in urban areas and admitted to hospital in January 2008 to March 2012.

Interventions "Hub and spoke" model for acute stroke care. In London hyperacute care was provided to all patients with stroke. In Greater Manchester hyperacute care was provided to patients presenting within four hours of developing symptoms of stroke.
\end{abstract}

Main outcome measures Mortality from any cause and at any place at 3,30 , and 90 days after hospital admission; length of hospital stay.
Results In London there was a significant decline in risk adjusted mortality at 3,30 , and 90 days after admission. At 90 days the absolute reduction was $-1.1 \%$ (95\% confidence interval -2.1 to -0.1 ; relative reduction $5 \%$ ), indicating 168 fewer deaths (95\% confidence interval 19 to 316 ) during the 21 month period after reconfiguration in London. In both areas there was a significant decline in risk adjusted length of hospital stay: -2.0 days in Greater Manchester ( $95 \%$ confidence interval -2.8 to $-1.2 ; 9 \%$ ) and -1.4 days in London ( -2.3 to $-0.5 ; 7 \%$ ). Reductions in mortality and length of hospital stay were largely seen among patients with ischaemic stroke.

Conclusions A centralised model of acute stroke care, in which hyperacute care is provided to all patients with stroke across an entire metropolitan area, can reduce mortality and length of hospital stay.

\section{Introduction}

Stroke is a leading cause of mortality and disability worldwide. ${ }^{1}$ Each year in England an estimated 125000 people have a stroke and 40000 of them die. ${ }^{2}$ Organised inpatient stroke unit care, which is provided by multidisciplinary teams that exclusively 
manage patients with stroke in a dedicated ward, is associated with better quality ${ }^{3}$ and reduced death and dependency. ${ }^{4}$ The Department of Health's National Stroke Strategy for England recommended major change in the system for stroke, identifying that care in a stroke unit was the single biggest factor that can improve outcomes after stroke. ${ }^{5}$ In several countries acute stroke services are being centralised as a means of improving access to organised inpatient stroke unit care. Hospitals of differing capability work together to create a centralised system of stroke care $^{6}$ in which patients are taken to central specialist units rather than the nearest hospital. Research in the United States, ${ }^{78}$ Canada, ${ }^{9}$ the Netherlands, ${ }^{10}$ Denmark, ${ }^{11}$ and Australia ${ }^{12}$ suggests this approach can improve provision of evidence based care processes for patients with stroke-for example, by increasing access to specialist care and thrombolysis. Other evidence suggests this approach is highly cost effective. ${ }^{13}$ While the improved clinical outcomes associated with organised inpatient stroke care are well documented, it is unknown if centralising acute stroke care to a small number of high volume specialist centres produces better clinical outcomes. ${ }^{14}{ }^{15}$ In addition, the wisdom of focusing on hyperacute stroke care has been questioned. ${ }^{16}$

In 2010, acute stroke services were centralised across two metropolitan areas of England (Greater Manchester, with a population of 2.68 million, and London, with 8.17 million). ${ }^{17}$ The changes in both areas entailed the selection of hospitals to become sites for specialist stroke services in multiple "hub and spoke" networks during the first 72 hours after stroke (fig $1 \Downarrow$ ).

Before the changes in London, 30 hospitals provided acute stroke care. After centralisation specialist care was provided to all patients in eight designated hyperacute stroke units 24 hours a day, seven days a week, with patients being assessed immediately by specialised stroke medical teams with the capacity for immediate brain imaging and thrombolysis when appropriate. Twenty four stroke units were designated to provide acute rehabilitation services, and eight of these were attached to a hyperacute stroke unit; five hospitals were no longer to provide acute stroke services. ${ }^{18}$ Hospital selection was guided by a modelling exercise whereby potential sites were identified based on determination of need, including the travel times involved, with the intention that no Londoner would be more than a 30 minute ambulance journey away from the nearest hyperacute stroke unit. ${ }^{18}$

In Greater Manchester, the original intention was also to treat all patients in hyperacute stroke units (one 24/7 comprehensive stroke centre and two primary stroke centres running $7 \mathrm{am}-7$ pm, Monday to Friday). Concerns about the number of patients being transported greater distances, difficulties with repatriation, and a view that access to specialist stroke centres was purely for thrombolysis, however, meant that patients presenting only within four hours of developing stroke symptoms were taken directly to a comprehensive stroke centre or primary stroke centre; all other patients were taken to one of 10 district stroke centres, which were designated to provide all aspects of post-thrombolysis stroke care.$^{19}$ No hospitals stopped providing stroke services entirely as a result of the centralisation process in Greater Manchester.

We investigated the impact of centralising acute stroke services in these two metropolitan areas on mortality and length of hospital stay. We used data for all patients in England who had a stroke during a 51 month period and controlled for trends in the rest of England during the same period and other factors that could affect outcomes. The study is part of a larger mixed methods evaluation. ${ }^{18}$

\section{Methods \\ Data}

We obtained patient level data from the hospital episode statistics database ${ }^{20}$ for all patients in England with a primary diagnosis of stroke defined with ICD-10 (international classification of diseases, 10th revision) codes I61 (intracerebral haemorrhage), I63 (cerebral infarction), or I64 (stroke, not specified as haemorrhage or infarction) from 1 January 2008 to 31 March 2012. We excluded subarachnoid haemorrhage (ICD-10 code I60) as it is managed through a different clinical pathway. ${ }^{21}$ The data were linked to mortality data supplied by the Office for National Statistics ${ }^{22}$ by using an anonymised unique patient identifier to identify deaths from any cause and at any place (hospital or otherwise) at 3, 30, and 90 days after hospital admission. Length of stay was measured in days as the difference between date of admission and date of discharge, including same day transfers between hospitals.

We started our analysis period in January 2008, after the publication of the National Stroke Strategy for the English NHS in December 2007, ${ }^{5}$ which was designed to lead to better emergency responses to stroke and acute stroke care around the country. ${ }^{23}$ Our data cover a 27 month period before the changes in Greater Manchester (which occurred in April 2010), and a 24 month period afterwards. In London they cover a 30 month period before the changes (July 2010) and a 21 month period afterwards. In both areas some hospitals began to reconfigure their services before these dates, and we control for this in our analysis using hospital and time fixed effects.

Our main analysis was confined to patients living in urban areas (defined as "urban-less sparse" using the urban/rural classification for England ${ }^{24}: 95 \%$ of patients with stroke in Greater Manchester and London lived in these areas compared with $75 \%$ in the rest of England). We did not restrict the analysis to any type of hospital (we included hospital fixed effects to allow for hospital differences), and we did not impose a minimum number of patients to be treated at each hospital (observations in the hospital level regressions were weighted by the number of patients). Over the period of the study, patients were treated at 11 hospitals in Greater Manchester, 38 in London, and 405 in the rest of England. Data were available for 258915 admissions, of which 17650 were in Greater Manchester ( 9413 before reconfiguration, 8237 afterwards) and 33698 were in London (18 672 and 15 026, respectively).

\section{Statistical analysis}

We evaluated whether centralisation of acute stroke services in Greater Manchester and London had an impact on mortality and length of hospital stay using regression analysis of difference-in-differences between regions ${ }^{25}$ to compare the changes over time in these areas with the change over time in the rest of England. The analysis was carried out at hospital level with quarterly observations of risk adjusted mortality and length of hospital stay; the risk adjustment was conducted at the patient level on all patients in the data. The approach is consistent with Medical Research Council guidelines for using natural experiments to evaluate population health interventions, ${ }^{26}$ and a similar method was used in an evaluation of the advancing quality initiative in the northwest of England. ${ }^{27}$

We calculated expected risks of death at 3,30, and 90 days after admission using patient level logistic regressions, including binary indicators for sex and age interactions (age measured in five year bands), stroke diagnosis using the first four digits of the primary ICD-10 diagnostic code (19 categories), Charlson 
inde $\mathrm{x}^{28}$ derived from secondary ICD-10 diagnostic codes, presence of 16 comorbidities included in the Charlson index, ethnic group (18 categories), deprivation quintile, ${ }^{29}$ and urban/rural classification ${ }^{24}$ (eight categories) of the area in which the patient lived (of 32482 lower layer super output areas in England). We ran the patient level regressions only on patients who had a stroke before the reorganisations in Greater Manchester and London so that the risk adjustment was not contaminated by the changes. The regression coefficients (derived from the logistic regressions for the period before implementation) were used to predict the probability of mortality for every patient (in periods before and after implementation). These were aggregated to create a dataset of the actual percentage of patients who died and the expected percentage by admitting hospital and quarter. We tested whether the reconfigurations had an impact on mortality using least squares regression of the actual minus expected mortality percentage (because we are modelling differences) against interaction terms between Greater Manchester and the period after reconfiguration and London and the period after reconfiguration. We included binary indicators for each of the 454 admitting hospitals (hospital fixed effects) and the 17 quarters (time fixed effects), and each observation was weighted by the number of patients treated at that hospital in that quarter. Standard errors were corrected for heteroskedasticity.

We used the same approach for length of hospital stay but estimated our risk adjustment equation using a generalised linear model (GLM) with gamma family and log link to account for data skewness. ${ }^{30}$ We experimented with other GLM specifications and a log transformation but the selected model gave the best fit in terms of residual plots and Akaike's information criterion. We added binary indicators for mortality at 3, 30, and 90 days after stroke to the risk equation and used the regression coefficients to predict expected mean length of hospital stay.

We undertook pre-trends tests to examine whether risk adjusted mortality and length of hospital stay had a different linear trend in Greater Manchester and London compared with the rest of England before the reconfigurations. We reran the models on every quarter before the reconfigurations and included linear time trends instead of binary indicators for quarter. We added interaction terms between Greater Manchester and the linear time trend and London and the linear time trend and tested the individual significance of the interaction terms. In every case they were non-significant $(\mathrm{P}>0.05)$.

\section{Results}

Patients in Greater Manchester and London were slightly younger than those in the rest of England, and those in London were less likely to be white British (table $1 \Downarrow$ ). The proportion of intracerebral haemorrhage strokes was slightly higher in London than in the rest of England, and slightly lower in Greater Manchester. Patients in Greater Manchester and London were less likely to live in deprived areas. Unadjusted outcomes show a small decline in mortality in London compared with the rest of England, and a small decline in length of hospital stay in Greater Manchester and London. There was some evidence of difference-in-differences with respect to age, sex, type of stroke, and deprivation in Greater Manchester and age, ethnic group, and type of stroke in London.

During the study period, risk adjusted mortality and length of hospital stay fell in Greater Manchester, London, and the rest of England (fig $2 \Downarrow$ ). In London there was a significantly larger absolute reduction in risk adjusted mortality at three days after admission than in the rest of England, by -1.0 percentage points (95\% confidence interval -1.5 to $-0.4 ; \mathrm{P}<0.001$; table $2 \Downarrow$ ).

There was also a significantly larger absolute reduction in risk adjusted mortality at 30 days $(-1.3,-2.2$ to $-0.4 ; \mathrm{P}=0.005)$ and 90 days after admission $(-1.1,-2.1$ to $-0.1 ; \mathrm{P}=0.03)$. These absolute differences represent relative reductions in mortality of $17 \%, 7 \%$, and $5 \%$, respectively, which equate to a total reduction of 146 deaths at three days $(95 \%$ confidence interval 67 to 225 ), 194 deaths at 30 days (60 to 328), and 168 deaths at 90 days ( 19 to 316 ) during the 21 months after reconfiguration in London. In Greater Manchester the changes in mortality after the reconfiguration of services were not significantly different to the changes seen in the rest of England during the same period.

In both areas there was a significantly larger decline in risk adjusted length of hospital stay compared with the rest of England. There was a significant reduction of -2.0 days (95\% confidence interval -2.8 to $-1.2 ; \mathrm{P}<0.001)$ in Greater Manchester and -1.4 days $(-2.3$ to $-0.5 ; \mathrm{P}=0.002)$ in London. These represent a $9 \%$ reduction in length of hospital stay in Greater Manchester and a 7\% reduction in London and imply 17685 fewer hospital days in Greater Manchester (95\% confidence interval 10717 to 24 652) and 22341 fewer in London (7887 to 36795 ) during the periods after reconfiguration (24 months in Greater Manchester, 21 months in London).

We reran our models on patients stratified by type of stroke and found that reductions in mortality and length of hospital stay were achieved largely among patients with ischaemic stroke, who comprised most cases ( $68 \%$ of the sample) (table $2 \Downarrow$ ). Point estimates of the reductions in mortality in London were higher for intracerebral haemorrhage than for ischaemic stroke but the effects for intracerebral haemorrhage were not significant. In Greater Manchester there was a significant increase in risk adjusted mortality at 30 days after cerebral infarction, but there were no significant differences at 3 and 90 days. We reran our models including 73558 patients who lived in rural areas, and this had little impact on the results (table 2). $\Downarrow$

\section{Discussion}

\section{Principal findings}

Since the centralisation of acute stroke services in two metropolitan areas, risk adjusted mortality and length of hospital stay fell in Greater Manchester, London, and the rest of the country. In London there was a significant reduction in mortality at 3,30, and 90 days after admission over and above the reduction seen in the rest of England; at 90 days the reduction in mortality was 1.1 percentage points. There was also a significant reduction in length of hospital stay of 1.4 days over and above the reduction seen in the rest of England. In Greater Manchester there was no impact on mortality over and above the change seen in the rest of England but there was a significant reduction in length of hospital stay by 2.0 days. Significant reductions in mortality and length of hospital stay were largely achieved among patients with ischaemic stroke.

\section{Strengths and weaknesses}

The main strengths of our study are that we used a large national dataset containing detailed information on outcomes and patient characteristics, and the robust quasi-experimental framework; these allowed us to control for trends in the rest of England and other factors that could affect outcomes during the same period. There are, however, several weaknesses. Firstly, the hospital episode statistics database does not include information on severity of stroke, which is an important predictor of mortality. ${ }^{31}$ 
Data collected after the reconfigurations from the Stroke Improvement National Audit Programme ${ }^{32}$ show that indicators of stroke severity, such as worst level of consciousness in first 24 hours after stroke and neurological deficits on admission, varied between Greater Manchester, London, and the rest of England (see table A, appendix), but there was no discernible trend over all the indicators. Despite this, and even though our outcomes are risk adjusted for several patient level factors and we accounted flexibly for differences between hospitals and trends over time, we cannot rule out the possibility that the differences in outcomes could be caused by variations in severity of stroke between Greater Manchester and London and the rest of England.

Secondly, we were unable to assess the impact of the reconfigurations on other outcomes, such as quality of life, disability, or neurological and functional impairment, as these measures were not collected in the hospital episode statistics database. We could, however, investigate the impact of the reconfigurations on mortality and length of hospital stay, outcomes that have not been previously reported.

Thirdly, the hospital episode statistics database includes only patients admitted to hospital. It does not include any information about patients who died before they reached the hospital, nor does it include information on the time of stroke; hence our analyses of mortality were based on time from admission. If patients with stroke in London were more likely to die before reaching the hospital because of longer travel distances to hyperacute stroke units then the effects of the reconfigurations on mortality would be overestimated. Evidence suggests this is unlikely because ambulance journey times for patients with stroke did not increase appreciably after the reconfiguration in London, with mean times from scene to hospital of 14 minutes from January 2005 to March $2008^{3}$ and 16 minutes from April 2011 to March 2012.33 Also, severity of stroke in London after reconfiguration was similar to the severity in the rest of England (table A, appendix); if more patients with severe stroke died in London before reaching the hospital the level of severity in the audit data for London would be lower than elsewhere.

Fourthly, length of hospital stay was measured as the difference between date of admission and date of discharge. We assumed that when patients were discharged from one hospital and readmitted to another hospital on the same day this was a transfer related to the original stroke, capturing the movement between components of the stroke care pathway (for example, between a hyperacute stroke unit and a stroke unit in London). Conversely, we assumed that when a subsequent admission occurred one or more days later after discharge this was a recurrent stroke (the risk of recurrence of stroke in the first month after discharge is $1.1-15 \%){ }^{34}$

Finally, there was a higher than expected number of patients with stroke per month in London during the period after reconfiguration. One possible reason is that after the reconfiguration London units treated more patients from surrounding areas, who might previously have gone to their local emergency department. This could bias the results in favour of the London reconfiguration if the additional admissions were for less severe strokes, but there are no discernible differences in severity between London, Greater Manchester, and the rest of England (table A, appendix).

\section{Comparison with other studies}

Our findings with respect to mortality in London are consistent with a cost effectiveness analysis of the reconfiguration of acute stroke services in London, ${ }^{13}$ which also found a significant improvement in survival in London at 90 days after admission. In that study the impact on survival was calculated with survival models estimated before and after the reconfiguration and an adjustment was applied to the difference in survival to account for national trends in mortality. Our study had a larger sample size, used national individual level data, had more patients in the period after reconfiguration in London, provides a more robust treatment of national trends via the quasi-experimental difference-in-difference design, and also examined the reconfiguration in Greater Manchester. Our findings are also consistent with a previous analysis based on national stroke audit data showing that patients admitted to stroke services with higher levels of organisation were more likely to receive high quality care and to have a reduced risk of death 30 days after stroke. $^{3}$

\section{Implications}

In London hyperacute stroke care was available to all patients, while in Greater Manchester it was available only to patients presenting within four hours of developing stroke symptoms. Our findings show that mortality outcomes were different in the two systems. In London, ambulance data indicate that in 2011-12, 98.7\% of patients with stroke were transported to the appropriate service: $95.7 \%$ were taken appropriately to a hyperacute stroke unit; $3 \%$ were taken appropriately to an emergency department; and $1.3 \%$ were taken to an emergency department when they should have been taken to a hyperacute stroke unit. ${ }^{33}$ A review of the first year of the new model in Greater Manchester reported that of the patients who presented with stroke within four hours, $36 \%$ were not taken to a comprehensive stroke centre or primary stroke centre. ${ }^{19}$ Hence, a higher proportion of patients than planned were admitted to district hospitals, where access to specialist expertise and care was more limited.

In addition, data on the achievement of processes measuring the quality of care that patients with stroke receive during the first 72 hours of care were collected between April 2011 and December 2012 as part of the Stroke Improvement National Audit Programme in England. ${ }^{32}$ A significantly higher proportion of patients in London received care that was compliant with the care processes compared with in Greater Manchester and the rest of England (which were broadly similar) (table B, appendix). This suggests that the centralised model of care in London was more closely adhered to and achieved greater compliance with care processes. There is evidence that better compliance with these measures is negatively correlated with mortality. ${ }^{3}$ According to the multivariate analyses these measures independently affect mortality, ${ }^{3}$ suggesting that different aspects of specialist care provided throughout the hyperacute stroke unit can separately affect patient outcomes. The upshot is that differences in mortality can be explained by the lower level of adherence in Greater Manchester or by differences between the two systems in terms of the access to hyperacute care for patients presenting after four hours of developing symptoms of stroke. This suggests that the type of system redesign and the extent of its implementation can affect patient outcomes and needs to be taken into account by those who are reorganising services. Additionally, while there is evidence that organised inpatient stroke care is beneficial to patients with intracerebral haemorrhage as well as ischaemic stroke, ${ }^{15}$ the improvements in outcomes from centralisation that we found in our study were largely among patients with ischaemic stroke. This could reflect the poorer prognosis in patients with intracerebral haemorrhage. ${ }^{35}$ 
In London we found some evidence that mortality was reduced at three days, suggesting that the reconfiguration might have delayed death among these patients but did not change the ultimate outcome. Alternatively, as point estimates of the reductions in mortality in London were higher for intracerebral haemorrhage than for ischaemic stroke but the effects were not significant, the wider confidence intervals might be because of the smaller numbers of patients in the data with this type of stroke.

On a different point, while the results were consistent when we included patients living in rural areas, they might be less relevant to services in rural settings. The greater travel times in rural areas make centralisation challenging and might necessitate other solutions, such as telemedicine, whereby consultation and triage can be conducted remotely by a stroke physician in a specialist stroke unit. ${ }^{36-38}$ Finally, our findings could also inform the centralisation of other healthcare services such as cancer care, ${ }^{39}$ cardiovascular care, ${ }^{40}$ major trauma care, ${ }^{41}$ and vascular surgery. ${ }^{42}$ Similar models of care adapted to local need could be applied to other large metropolitan areas and to other conditions.

Future research would be beneficial to examine the impact of centralising acute stroke services on disability after stroke and also on achievement of care processes and quality of care. Further information on the cost and cost effectiveness of centralisation would also be useful for policy makers and commissioners.

Contributors: SM, NJF, RMH and AIGR designed the study. SM carried out the analysis of the hospital episode statistics data and drafted the initial manuscript. AIGR carried out the analysis of the Stroke Improvement National Audit Programme data. RMH formatted the hospital episode statistics data and contributed to the statistical analysis. All authors made substantial contributions to the study design and interpretation of the findings and contributed to the drafting of the article or critical revision for important intellectual content, gave final approval of the version to be published, and agree to be accountable for all aspects of the work in ensuring that questions related to the accuracy or integrity of any part of the article are appropriately investigated and resolved. NJF is guarantor.

Funding: This paper presents independent research commissioned by the health services and delivery research programme of the National Institute for Health Research (NIHR), funded by the Department of Health (study reference 10/1009/09). The views expressed are those of the authors and not necessarily those of the NHS, the NIHR, or the Department of Health. CDAW was supported by the NIHR Biomedical Research Centre at Guy's and St Thomas' NHS Foundation Trust and King's College London, and also by the NIHR Collaboration for Leadership in Applied Health Research and Care Funding scheme.

Competing interests: All authors have completed the ICMJE uniform disclosure form at http://www.icmje.org/coi_disclosure.pdf and declare: no support from any organisation for the submitted work; no financial relationships with any organisations that might have an interest in the submitted work in the previous three years, and no other relationships or activities that could appear to have influenced the submitted work. AGR is the national clinical director of stroke in England, and London stroke clinical director. PJT was clinical lead for stroke in Greater Manchester up to 2013, and led the Greater Manchester stroke service redesign from 2007. The sponsor approved all aspects of the study protocol and any amendments thereto, but played no other role in design or conduct of the study.

Ethical approval: The study received ethical approval in September 2011 from the London East NHS research ethics committee (ref 11/LO/1396).
Data sharing: No additional data available.

Transparency statement: The last author (the manuscript's guarantor) affirms that this manuscript is an honest, accurate, and transparent account of the study being reported; that no important aspects of the study have been omitted; and that any discrepancies from the study as planned (and, if relevant, registered) have been explained.

1 Mackay J, Mensah GA. The atlas of heart disease and stroke. World Health Organization, 2004.

2 Townsend N, Wickramasinghe K, Bhatnagar P, Smolina K, Nichols M, Leal J, et al. Coronary heart disease statistics. British Heart Foundation, 2012.

3 Bray BD, Ayis S, Campbell J, Hoffman A, Roughton M, Tyrrell PJ, et al. Associations between the organisation of stroke services, process of care, and mortality in England: prospective cohort study. BMJ 2013;346:f2827.

4 Langhorne P, Fearon P, Ronning OM, Kaste M, Palomaki H, Vemmos K, et al. Stroke unit care benefits patients with intracerebral hemorrhage systematic review and meta-analysis. Stroke 2013;44:3044-9.

5 Department of Health. National Stroke Strategy. DoH, 2007. http://clahrc-gm.nihr.ac.uk/ cms/wp-content/uploads/DoH-National-Stroke-Strategy-2007.pdf.

6 Higashida R, Alberts MJ, Alexander DN, Crocco TJ, Demaerschalk BM, Derdeyn CP, et al. Interactions within stroke systems of care a policy statement from the American Heart Association/American Stroke Association. Stroke 2013;44:2961-84.

7 Prabhakaran S, O'Neill K, Stein-Spencer L, Walter J, Alberts MJ. Prehospital triage to primary stroke centers and rate of stroke thrombolysis. JAMA Neurol 2013;70:1126-32.

8 Smith EE, Dreyer P, Prvu-Bettger J, Abdullah AR, Palmeri G, Goyette L, et al. Stroke center designation can be achieved by small hospitals: the Massachusetts experience. Crit Pathw Cardiol 2008;7:173-7.

9 Weir N, Buchan A. A study of the workload and effectiveness of a comprehensive acute stroke service. J Neurol Neurosurg Psychiatry 2005;76:863-5.

10 Lahr MM, Luijckx G-J, Vroomen PC, van der Zee D-J, Buskens E. Proportion of patients treated with thrombolysis in a centralized versus a decentralized acute stroke care setting. Stroke 2012;43:1336-40.

11 Bruins Slot K, Murray V, Boysen G, Berge E. Thrombolytic treatment for stroke in the Scandinavian countries. Acta Neurol Scand 2009;120:270-6.

12 Cadilhac DA, Purvis T, Kilkenny MF, Longworth M, Mohr K, Pollack M, et al. Evaluation of rural stroke services does implementation of coordinators and pathways improve care in rural hospitals? Stroke 2013;44:2848-53.

13 Hunter RM, Davie C, Rudd A, Thompson A, Walker H, Thomson N, et al. Impact on clinical and cost outcomes of a centralized approach to acute stroke care in London: a comparative effectiveness before and after model. PloS One 2013;8:e70420.

14 Lahr MH, Luijckx G-J, Vroomen PAJ, Zee D-J, Buskens E. The chain of care enabling tPA treatment in acute ischemic stroke: a comprehensive review of organisational models. J Neurol 2013;260:960-8.

15 Langhorne P, Lewsey JD, Jhund PS, Gillies M, Chalmers JW, Redpath A, et al. Estimating the impact of stroke unit care in a whole population: an epidemiological study using routine data. J Neurol Neurosurg Psychiatry 2010;81:1301-5.

16 Sudlow C, Warlow C. Getting the priorities right for stroke care. BMJ 2009;338.

17 Office for National Statistics. 2011 Census: usual resident population, local authorities in England and Wales. ONS, 2012. www.ons.gov.uk/ons/rel/census/2011-census/keystatistics-for-local-authorities-in-england-and-wales/rft-table-ks101ew.xls.

18 Fulop N, Boaden R, Hunter R, McKevitt C, Morris S, Pursani N, et al. Innovations in major system reconfiguration in England: a study of the effectiveness, acceptability and processes of implementation of two models of stroke care. Implement Sci 2013;8:5.

19 Greater Manchester and Cheshire Cardiac and Stroke Network Support Team. Development of stroke services in Greater Manchester: twelve month review. Greater Manchester and Cheshire Cardiac and Stroke Network, 2011.

20 Health and Social Care Information Centre. Hospital episode statistics. www.hscic.gov. uk/hes.

21 Intercollegiate Stroke Working Party. National clinical guideline for stroke, 4th edition. Royal College of Physicians, 2012.

22 Health and Social Care Information Centre. Linked HES-ONS mortality data. www.hscic. gov.uk/article/2677/Linked-HES-ONS-mortality-data.

23 National Audit Office. Progress in improving stroke care: Department of Health, HC 291, Report by Comptroller and Auditor General, Session 2009-10. Stationery Office, 2010.

24 Office for National Statistics. 2001 Rural-Urban Classification. www.ons.gov.uk/ons/guidemethod/geography/products/area-classifications/rural-urban-definition-and-la/index.html.

25 Imbens GW, Wooldridge JM. Recent developments in the econometrics of program evaluation. National Bureau of Economic Research, 2008.

26 Craig P, Cooper C, Gunnell D, Haw S, Lawson K, Macintyre S, et al. Using natural experiments to evaluate population health interventions: new Medical Research Council guidance. J Epidemiol Community Health 2012;661182-6.

27 Sutton M, Nikolova S, Boaden R, Lester H, McDonald R, Roland M. Reduced mortality with hospital pay for performance in England. N Engl J Med 2012;367:1821-8.

28 Quan H, Sundararajan V, Halfon P, Fong A, Burnand B, Luthi J-C, et al. Coding algorithms for defining comorbidities in ICD-9-CM and ICD-10 administrative data. Med Care 2005;43:1130-9.

29 Data.gov.uk. Index of multiple deprivation 2004. http://data.gov.uk/dataset/imd_2004.

30 Barber J, Thompson S. Multiple regression of cost data: use of generalised linear models. $J$ Health Serv Res Policy 2004;9:197-204.

31 Fonarow GC, Pan W, Saver JL, Smith EE, Reeves MJ, Broderick JP, et al. Comparison of 30-day mortality models for profiling hospital performance in acute ischemic stroke with vs without adjustment for stroke severity. JAMA 2012;308:257-64.

32 Royal College of Physicians. SINAP: latest results. RCP, 2013. www.rcplondon.ac.uk/ resources/sinap-latest-results.

33 Ramelyte M, Virdi G, Fothergill R, Thomson N. Stroke annual report: 2011/2012. London Ambulance Service NHS Trust, 2012.

34 Mohan KM, Wolfe CD, Rudd AG, Heuschmann PU, Kolominsky-Rabas PL, Grieve AP. Risk and cumulative risk of stroke recurrence a systematic review and meta-analysis. Stroke 2011;42:1489-94.

35 Sacco S, Marini C, Toni D, Olivieri L, Carolei A. Incidence and 10-year survival of intracerebral hemorrhage in a population-based registry. Stroke 2009;40:394-9. 


\section{What is already known on this topic}

Organised inpatient stroke unit care is associated with higher quality care and reduced death and dependency

Acute stroke services are being centralised in several countries as a means of improving access to organised inpatient stroke unit care but it is not known if this affects mortality and length of hospital stay

In 2010, acute stroke services were centralised across two metropolitan areas of England (Greater Manchester and London)

\section{What this study adds}

In London, where hyperacute stroke care was provided to all patients, there was a reduction in mortality and length of hospital stay

In Greater Manchester, where hyperacute stroke care was provided to patients presenting within four hours of developing stroke symptoms, there was no impact on mortality but length of stay in hospital fell

36 Audebert HJ, Schwamm L. Telestroke: scientific results. Cerebrovasc Dis 2009;27(suppl 4):15-20.

37 Demaerschalk BM, Miley ML, Kiernan T-EJ, Bobrow BJ, Corday DA, Wellik KE, et al, STARR Coinvestigators. Stroke telemedicine. Mayo Clin Proc 2009;84:53-64.

38 Silva GS, Farrell S, Shandra E, Viswanathan A, Schwamm LH. The status of telestroke in the united states: a survey of currently active stroke telemedicine programs. Stroke 2012;43:2078-85.

39 Woo YL, Kyrgiou M, Bryant A, Everett T, Dickinson HO. Centralisation of services for gynaecological cancer. Cochrane Database Syst Rev 2012;3:CD007945.

40 Fosbol EL, Granger CB, Jollis JG, Monk L, Lin L, Lytle BL, et al. The impact of a statewide pre-hospital STEMI strategy to bypass hospitals without percutaneous coronary intervention capability on treatment times. Circulation 2013;127:604-12.

41 Gabbe BJ, Biostat GD, Simpson PM, Sutherland AM, Dip G, Wolfe R, et al. Improved functional outcomes for major trauma patients in a regionalized, inclusive trauma system. Ann Surg 2012;255:1009-15.
42 Williams D. Major reconfiguration plans emerging across England. HJS, 2011. www.hsj. co.uk/acute-care/major-reconfiguration-plans-emerging-across-england/5037539.article.

Accepted: 14 July 2014

\section{Cite this as: BMJ 2014;349:g4757}

This is an Open Access article distributed in accordance with the Creative Commons Attribution Non Commercial (CC BY-NC 3.0) license, which permits others to distribute, remix, adapt, build upon this work non-commercially, and license their derivative works on different terms, provided the original work is properly cited and the use is non-commercial. See: http://creativecommons.org/licenses/by-nc/3.0/. 


\section{Tables}

Table 1| Characteristics of patients before and after reconfiguration of acute stroke services in Greater Manchester and London compared with rest of England

\begin{tabular}{|c|c|c|c|c|c|c|c|c|c|c|c|}
\hline & \multicolumn{3}{|c|}{ Rest of England } & \multicolumn{3}{|c|}{ Greater Manchester } & \multicolumn{3}{|c|}{ London } & \multicolumn{2}{|c|}{ Difference-in-differences ${ }^{*}$} \\
\hline & $\begin{array}{c}\text { Before } \\
(n=122 \\
084)\end{array}$ & $\begin{array}{c}\text { After } \\
(n=85 \\
483)\end{array}$ & Difference & $\begin{array}{c}\text { Before } \\
(n=9413)\end{array}$ & $\begin{array}{c}\text { After } \\
(n=8237)\end{array}$ & Difference & $\begin{array}{c}\text { Before } \\
(n=18 \\
672)\end{array}$ & $\begin{array}{c}\text { After } \\
(n=15 \\
026)\end{array}$ & Difference & $\begin{array}{l}\text { Manchester } \\
\text { minus rest } \\
\text { of England }\end{array}$ & $\begin{array}{l}\text { London } \\
\text { minus rest } \\
\text { of England }\end{array}$ \\
\hline \multicolumn{12}{|c|}{ Unadjusted outcomes } \\
\hline \multicolumn{12}{|c|}{ Unadjusted mortality: } \\
\hline At 3 days (\%) & 6.6 & 5.7 & -0.9 & 6.3 & 5.6 & -0.7 & 5.8 & 4.6 & -1.2 & 0.2 & -0.3 \\
\hline At 30 days (\%) & 19.2 & 16.9 & -2.4 & 18.1 & 16.5 & -1.6 & 16.8 & 14.1 & -2.8 & 0.7 & -0.4 \\
\hline At 90 days (\%) & 25.8 & 22.7 & -3.1 & 25.2 & 21.9 & -3.3 & 23.0 & 19.4 & -3.6 & -0.2 & -0.4 \\
\hline $\begin{array}{l}\text { Mean } \\
\text { unadjusted } \\
\text { length of } \\
\text { hospital stay } \\
\text { (days) }\end{array}$ & 21.0 & 18.4 & -2.6 & 21.7 & 17.7 & -4.0 & 20.6 & 17.8 & -2.8 & -1.4 & -0.2 \\
\hline \multicolumn{12}{|c|}{ Patient characteristics } \\
\hline \multicolumn{12}{|l|}{ Age (year): } \\
\hline Mean & 75.6 & 75.3 & -0.3 & 74.3 & 73.9 & -0.4 & 73.0 & 73.3 & 0.2 & -0.1 & 0.5 \\
\hline$\geq 75(\%)$ & 60.6 & 59.3 & -1.3 & 56.0 & 53.6 & -2.4 & 54.3 & 54.4 & 0.1 & -1.1 & 1.4 \\
\hline Female (\%) & 53.0 & 52.2 & -0.8 & 52.6 & 50.4 & -2.1 & 51.0 & 49.8 & -1.2 & -1.4 & -0.4 \\
\hline $\begin{array}{l}\text { White British } \\
\text { ethnic group } \\
\text { (\%) }\end{array}$ & 84.3 & 86.4 & 2.1 & 82.9 & 84.2 & 1.2 & 58.5 & 55.0 & -3.5 & -0.9 & -5.6 \\
\hline $\begin{array}{l}\text { Intracerebral } \\
\text { haemorrhage } \\
(\%) \dagger\end{array}$ & 12.8 & 12.7 & -0.2 & 11.5 & 11.7 & 0.2 & 15.7 & 14.8 & -0.9 & 0.3 & -0.7 \\
\hline $\begin{array}{l}\text { Cerebral } \\
\text { infarction (\%)‡ }\end{array}$ & 65.1 & 71.6 & 6.5 & 61.6 & 64.4 & 2.8 & 68.9 & 76.1 & 7.2 & -3.7 & 0.7 \\
\hline $\begin{array}{l}\text { Stroke, not } \\
\text { specified as } \\
\text { haemorrhage or } \\
\text { infarction (\%)§ }\end{array}$ & 22.1 & 15.7 & -6.3 & 26.9 & 23.9 & -3.0 & 15.4 & 9.1 & -6.3 & 3.3 & 0.0 \\
\hline $\begin{array}{l}\text { Charlson index } \\
\text { (mean score) }\end{array}$ & 1.9 & 1.9 & 0.0 & 2.0 & 2.0 & 0.0 & 2.0 & 2.0 & 0.0 & 0.0 & 0.0 \\
\hline $\begin{array}{l}\text { Most deprived } \\
\text { fifth (\%)ף }\end{array}$ & 17.2 & 17.6 & 0.4 & 8.4 & 10.3 & 1.9 & 12.6 & 13.2 & 0.6 & 1.5 & 0.2 \\
\hline
\end{tabular}

*Unadjusted difference-in-differences between regions showing change over time in Greater Manchester and London minus change over time in rest of England. †Primary diagnosis of stroke with ICD-10 diagnostic code 161.

¥Primary diagnosis of stroke with ICD-10 diagnostic code 163.

§Primary diagnosis of stroke with ICD-10 diagnostic code 164.

IBased on 32482 small areas (lower layer super output areas) of residence in England. 
Table 2| Absolute differences in risk adjusted mortality and length of hospital stay between Greater Manchester and London compared with rest of England before and after reconfiguration of acute stroke services

Difference-in-differences* $(95 \% \mathrm{Cl})$, P value

Greater Manchester minus rest of England

London minus rest of England

All stroke types combined; patients living in urban areas only

Risk adjusted mortality:

\begin{tabular}{|c|c|c|}
\hline At 3 days & $-0.04(-0.7$ to 0.6$), 0.90$ & $-1.0(-1.5$ to -0.4$),<0.001$ \\
\hline At 30 days & $0.8(-0.3$ to 1.9$), 0.15$ & $-1.3(-2.2$ to -0.4$), 0.005$ \\
\hline At 90 days & $0.1(-1.1$ to 1.3$), 0.89$ & $-1.1(-2.1$ to -0.1$), 0.03$ \\
\hline Risk adjusted length of hospital stay (days) & $-2.0(-2.8$ to -1.2$),<0.001$ & $-1.4(-2.3$ to -0.5$), 0.002$ \\
\hline \multicolumn{3}{|c|}{ Intracerebral haemorrhaget; patients living in urban areas only } \\
\hline \multicolumn{3}{|l|}{ Risk adjusted mortality: } \\
\hline At 3 days & $0.4(-2.9$ to 3.8$), 0.80$ & $-3.3(-5.7$ to -0.9$), 0.006$ \\
\hline At 30 days & $-1.1(-5.1$ to 2.9$), 0.60$ & $-2.0(-4.8$ to 0.8$), 0.16$ \\
\hline At 90 days & 0.3 (-4.3 to 3.8$), 0.90$ & $-1.1(-4.0$ to 1.7$), 0.44$ \\
\hline Risk adjusted length of hospital stay (days) & $-1.3(-3.7$ to 1.0$), 0.27$ & $-0.7(-2.4$ to 0.9$), 0.39$ \\
\hline \multicolumn{3}{|c|}{ Cerebral infarction¥; patients living in urban areas only } \\
\hline \multicolumn{3}{|l|}{ Risk adjusted mortality: } \\
\hline At 3 days & $0.5(-0.2$ to 1.1$), 0.14$ & $-0.8(-1.2$ to -0.3$), 0.001$ \\
\hline At 30 days & 1.9 (0.6 to 3.2$), 0.004$ & $-1.3(-2.2$ to -0.3$), 0.01$ \\
\hline At 90 days & $1.1(-0.4$ to 2.5$), 0.14$ & $-1.1(-2.2$ to -0.03$), 0.04$ \\
\hline Risk adjusted length of hospital stay (days) & $-2.6(-3.6$ to -1.5$),<0.001$ & $-1.4(-2.4$ to -0.3$), 0.009$ \\
\hline \multicolumn{3}{|c|}{ Stroke, not specified as haemorrhage or infarction§; patients living in urban areas only } \\
\hline \multicolumn{3}{|l|}{ Risk adjusted mortality: } \\
\hline At 3 days & $-0.8(-2.5$ to 0.9$), 0.34$ & $0.02(-2.0$ to 2.0$), 0.98$ \\
\hline At 30 days & $-0.1(-2.6$ to 2.4$), 0.94$ & $-1.3(-4.3$ to 1.7$), 0.40$ \\
\hline At 90 days & $-1.2(-3.9$ to 1.5$), 0.39$ & $-2.2(-5.4$ to 1.0$), 0.18$ \\
\hline Risk adjusted length of hospital stay (days) & $-0.9(-2.4$ to 0.5$), 0.21$ & $-2.2(-3.7$ to -0.7$), 0.004$ \\
\hline \multicolumn{3}{|c|}{ All stroke types combined; patients living in urban and rural areas } \\
\hline \multicolumn{3}{|l|}{ Risk adjusted mortality: } \\
\hline At 3 days & $-0.1(-0.7$ to 0.6$), 0.94$ & $-1.0(-1.5$ to -0.4$), 0.001$ \\
\hline At 30 days & $0.8(-0.2$ to 1.9$), 0.13$ & $-1.2(-2.1$ to -0.2$), 0.01$ \\
\hline At 90 days & $0.1(-1.2$ to 1.4$), 0.87$ & $-1.0(-2.0$ to -0.1$), 0.04$ \\
\hline Risk adjusted length of hospital stay (days) & $-2.1(-2.9$ to -1.3$),<0.001$ & $-1.4(-2.3$ to -0.5$), 0.003$ \\
\hline
\end{tabular}

*Values are risk adjusted difference-in-differences between regions showing change over time in Greater Manchester and London minus change over time in rest of England.

†Primary diagnosis of stroke with ICD-10 diagnostic code I61.

¥Primary diagnosis of stroke with ICD-10 diagnostic code 163.

§Primary diagnosis of stroke with ICD-10 diagnostic code 164. 


\section{Figures}

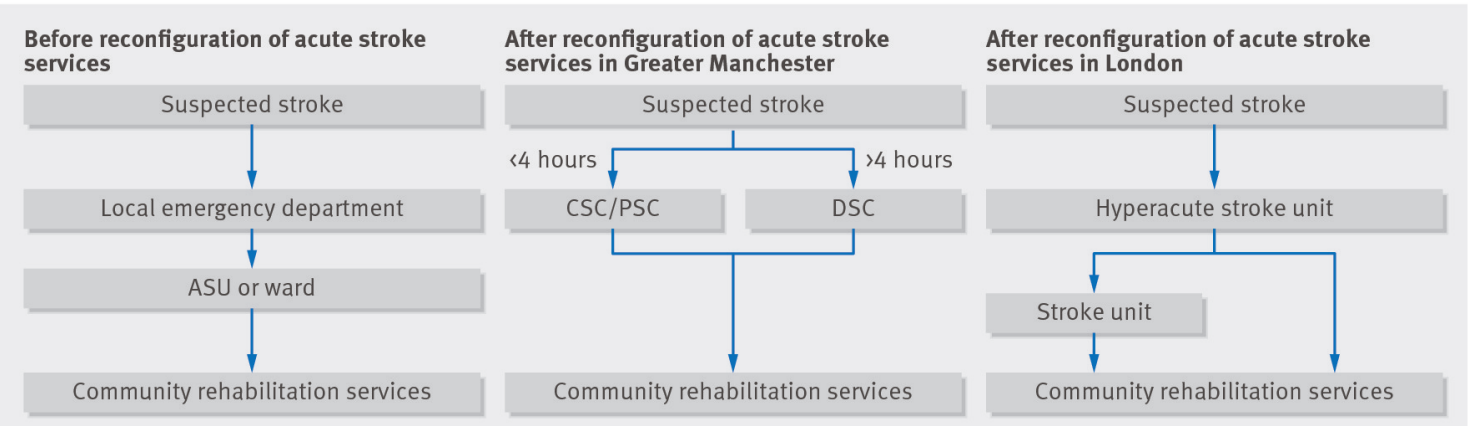

Fig 1 Summary of acute stroke pathway in Greater Manchester and London before and after reconfiguration of acute stroke services. $\mathrm{ASU}=$ acute stroke unit, $\mathrm{CSC}=$ comprehensive stroke centre, $\mathrm{PSC}=$ primary stroke centre, $\mathrm{DSC}=$ district stroke centre. Before the centralisation of acute stroke services in both Greater Manchester and London, patients with suspected stroke were taken to the nearest emergency department to receive stroke care. They were then sent to either an acute stroke unit or a regular hospital ward for treatment before being discharged for community rehabilitation. After the reorganisation in Greater Manchester patients presenting within four hours of developing stroke symptoms are sent to the comprehensive stroke centre or a primary stroke centre for hyperacute care. Once stable, they are repatriated to a district stroke centre, a nursing home, or their own home for community rehabilitation. Patients presenting outside the four-hour window are taken to the nearest DSC, receiving similar treatment to that provided before the reorganisation. After the reorganisation in London, patients presenting with stroke symptoms at any time are taken to a hyperacute stroke unit for assessment and treatment, then repatriated to a stroke Unit, to a nursing home, or to their own home for community rehabilitation 

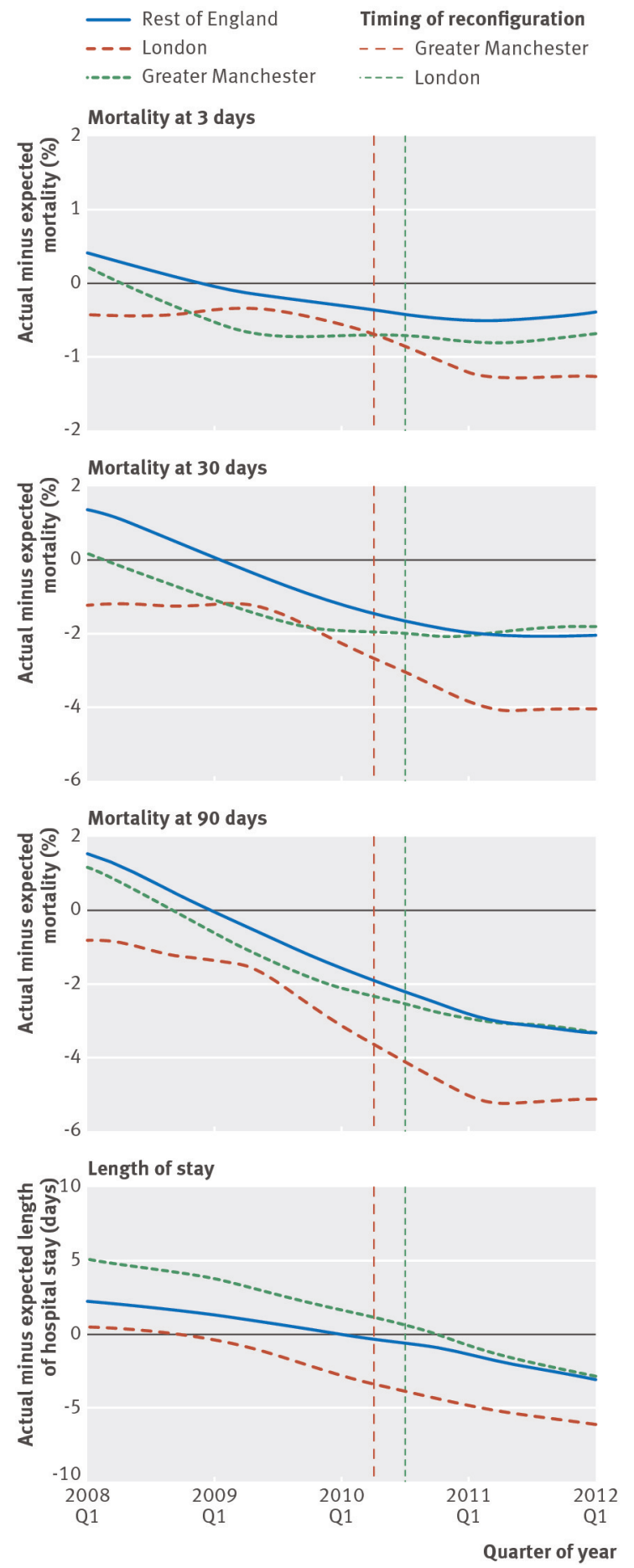

Fig 2 Risk adjusted mortality at 3, 30, and 90 days and length of hospital stay in Greater Manchester, London, and the rest of England by quarter. Differences between actual mortality and length of hospital stay and expected values derived from patient level risk equations are shown. In both areas some hospitals began to reconfigure their services before these dates; this is controlled for by using hospital and time fixed effects 